\title{
Neurophysiological, cognitive-behavioral and neurochemical effects in practitioners of transcendental meditation - A literature review
}

\author{
D. Amanda Cristina Mosini \\ (iD) Marcelo Saad² \\ Camilla Casaletti Braghetta ${ }^{2}$ \\ (iD) Roberta de Medeiros ${ }^{3}$ \\ Mario Fernando Prieto Peres 4 \\ (iD) Frederico Camelo Leão ${ }^{5}$
}

1. Laboratory of Neurobiology, Department of Physiology, Escola Paulista de Medicina, Universidade Federal de São Paulo, São Paulo, SP, Brasil 2. Spiritist-Medical Association of São Paulo, SP, Brasil

3. University Center São Camilo, São Paulo, SP, Brasil 4. Albert Einstein Hospital, São Paulo, SP, Brasil 5. Institute of Psychiatry, Faculty of Medicine of the University of São Paulo, SP, Brasil

http://dx.doi.org/10.1590/1806-9282.65.5.706

\section{SUMMARY}

The term meditation can be used in many different ways, according to the technique to which it refers. Transcendental Meditation (MT) is one of these techniques. TM could serve as a model for research on spiritual meditation, unlike the meditation techniques based on secular knowledge. The purpose of the present study is to conduct a bibliographic review to organize scientific evidence on the effects of TM on neurophysiology, neurochemistry, and cognitive and behavioral aspects of its practitioners. To conduct this critical narrative review of the literature, we searched for scientific papers on the PubMed database of the National Center for Biotechnology Information. The keywords used in the search were Transcendental Meditation, Neuroscience of meditation e Meditation and behavior. We selected 21 papers that analyzed different aspects that could be altered through meditation practice. We concluded that TM has positive and significant documentable neurochemical, neurophysiological, and cognitive-behavioral effects. Among the main effects are the reduction of anxiety and stress (due to the reduction of cortisol and norepinephrine levels), increase of the feeling of pleasure and well-being (due to the increase of the synthesis and release of dopamine and serotonin), and influence on memory recall and possible consolidation. Further studies are needed using creative and innovative methodological designs that analyze different neural circuitry and verify the clinical impact on practitioners.

KEYWORDS: Meditation. Mind-body therapies. Complementary therapies. Neurophysiology.

\section{INTRODUCTION}

The term meditation can be used in various ways, according to the technique to which it refers. According to Johnson', meditation can be defined as: "The wide range of activities that seek to expand and emphasize the mind's reach and its possible functioning, achieved mostly by methods of sensory-mo- tor discipline, such as remaining seated in silence, relaxing, closing one's eyes, breathing consciously and adopting an object of consciousness [...] it is first and foremost a technique, a way of developing consciousness." Transcendental Meditation (TM) is one of these meditation techniques, like those associated 
with yoga, tantra, Tibetan Buddhism and Zen Buddhism².

During meditation, mental activity is naturally installed while attention is maintained or even increased. Studies show that meditation produces a specific pattern of physiological responses that involve several biological systems. More frequent mechanisms suggest that meditation produces effects that are beneficial for the autonomic, endocrine, neurological, cardiovascular, and psychological metabolism ${ }^{3}$.

Transcendental meditation was brought to the west by the Indian Maharishi Mahesh Yogi. It became very popular in the 1960s, and in the 1970s scientific research linking its practice with the physiological effects caused was presented for the first time $^{4}$. This practice has been described as a simple and natural method to establish a peaceful and deep rest, so there is full mental awareness ${ }^{5}$.

While Western psychology describes three states of consciousness (sleep, dream, and wakefulness), in eastern philosophy and mystical traditions, another state is considered the "fourth state of consciousness," which could be achieved through the practice of meditation ${ }^{6}$. The purpose of meditation is the elimination or reduction of thought processes, the deceleration of the inner dialog of the mind. This reduction of the thought process aims to increase this state of higher consciousness and, thus, could lead to a great sense of physical and mental tranquility ${ }^{7}$.

Meditation has a history of association with religious and spiritual practices and disciplines. Practitioners of TM affirm that they do not adhere to any specific religious practice but emphasize the spiritual dimension of this specific technique ${ }^{8}$.

There are several understandings about what spirituality is. Unruh et al. ${ }^{9}$ analyzed concepts of spirituality in research on the area of health and observed that the notions of transcendence and sense of connection were at the center of the understanding of spirituality in this field of study. Transcendence refers to the idea of an experience field outside the material existence of everyday life, and connectedness refers to the perception of being connected to people, nature, the cosmos - the ability to have an intrapersonal, interpersonal, and transpersonal connection.

The spiritual characteristic inherent to the practice of TM aims to maintain the practitioner less involved in physical and mundane concerns, focusing on something greater, their own position within a universe, a notion that relates to the concept of transcendence. In this context, TM can be regarded as a model for research on spiritual meditation, unlike meditation techniques based on a secular understanding.

In a meta-analysis that examined meditation techniques, beneficial effects were found more consistently after the use of TM, which is a practice spiritually substantiated, than in individuals who used techniques of secular meditation or relaxation ${ }^{10}$.

The range of positive effects reported after the practice of TM is wide and include reduction of anxiety $^{11}$, increase of self-accomplishment ${ }^{12}$, increased creativity and concentration ${ }^{13}$, increased in autonomic stability ${ }^{14}$, significant decrease of cortisol and norepinephrine plasma levels ${ }^{15}$, increased serotonin and dopamine ${ }^{16}$, blood pressure control ${ }^{17}$, among others.

TM is a technique that has been little studied if compared to standardized secular practices, such as mindfulness-based stress reduction (MBSR). The results of these studies are scattered in different publications, and some are ignored by many scholars due to the significant lack of knowledge on the existence of this particular technique. Thus, the objective of the present study was to conduct a literature review to organize the scientific evidence on the effects of MT on neurophysiology, neurochemistry, and cognitive and behavioral aspects of its practitioners. The study also aims to propose a conceptual model to provide bases for future studies on possible mechanisms of MT.

Transcendental meditation presents a differential, which is the fact that it does not require disciplined postures and breathing, or even the control of concentration. The technique flows naturally and spontaneously, so it is not an exhaustive or uncomfortable practice. It consists of meditation induced by mantras and dismisses the classical postures and the need for absolute concentration, which are found in other meditative techniques; thus, it can be practiced at any place and time.

\section{METHODS}

For this critical narrative review of the literature, we searched scientific articles in the PubMed database of the National Center for Biotechnology Information (NCBI) in June 2018. The keywords used for the search were Transcendental Meditation, Neuroscience of meditation, and Meditation and behavior. The 
inclusion criteria were studies that reported the neurophysiological and behavioral effects of the practice of transcendental meditation. After selecting the articles, they were grouped and described in three different sections: neurophysiological, neurochemical, and cognitive/behavioral aspects.

The articles were read, evaluated, and described in relation to aspects of methodological quality and other parameters, such as techniques used, factors for the inclusion of participants and, finally, the results obtained. We found 21 articles relating neurophysiological, neurochemical, cognitive and behavioral aspects with practices of transcendental meditation. These studies analyzed different aspects that could be altered by meditative practice (Table 1).

Five aspects of the methodological quality of the studies were assessed, as described in Table 2.

It is observed from Table 2 that, of the 20 articles analyzed, 19 had a control group. In these, the controls were individuals randomly selected who did not have the habit of practicing transcendental meditation and who remained at rest with their eyes closed; the experimental groups were meditation practitioners.

\section{RESULTS \& DISCUSSION}

Neurochemical and neurophysiological aspects

Electrophysiology experiments showed that MT promotes greater stimulation in alpha waves in the prefrontal and temporal areas ${ }^{19}$, which are related to concentration, sense of social responsibility, and decision-making. This higher cortical stimulation in the prefrontal region added to an increase in the glutamatergic synthesis and release, results in the stimulation of the arcuate nucleus in the hippocampus, an area mediated by circulating hormones and metabolites, in addition to receiving direct stimulation of the lateral and paraventricular nuclei of the hypothalamus. The lateral nuclei interact based on

TABLE 1. ARTICLES DIVIDED BASED ON THE ASPECTS ADDRESSED

\begin{tabular}{l|l} 
Aspect addressed & Yes \\
\hline Cognitive aspects & 3 \\
\hline Neurochemical aspects & 6 \\
\hline Neurophysiological aspects & 12 \\
\hline Behavioral aspects & 7 \\
\hline
\end{tabular}

afferencies from the dopaminergic reward system, stimuli related to memory, motivation, and learning, signals from the nucleus accumbens, amygdala, and nucleus pallidus; these nuclei are directly correlated with the production of neurotensin, orexin, hypocretin, histamine, melatonin, and beta-endorphins with the arcuate nucleus.

Electroencephalography experiments have shown that in MT there is an increase in the activation of the prefrontal cortex and anterior cingulate gyrus $^{20}$. Using positron emission tomography, a decrease in blood flow in the prefrontal cortex (PFC) was observed, apparently associated with the attention to the mantra ${ }^{21}$. Some imaging studies suggest that the PFC, especially the right hemisphere, is related to attention-dependent activities ${ }^{22}$. The cingulate gyrus also features a similar function and is involved in focusing attention ${ }^{23}$. Studies have shown that, after the practice of meditation, the bilateral activity of the $\mathrm{CPF}$ and the cingulate gyrus presented increased activity ${ }^{24}$.

Several studies have demonstrated that the CPF can directly stimulate the thalamic reticular nucle$u^{25}$, this activation may be related to the production and release of glutamate, the main excitatory neurotransmitter ${ }^{26}$. The thalamus, considered the sensory station, uses the glutamate released by activating the synapses it has with other structures ${ }^{27}$. During meditation, the increased activity of the CPF promotes the concomitant increase in the activity of the reticular nucleus, which in turn secretes the neurotransmitter gamma-aminobutyric acid (GABA), the main inhibitory neurotransmitter, in the lateral posterior and geniculate nuclei, increasing the activation of the reticular nucleus via the superior parietal lobe (PSPL) $)^{28.29}$.

Some studies have shown the increase in GABAergic concentration during meditation ${ }^{30}$, resulting in a possible reduction of external stimuli to the visual cortex and PSPL, increasing the sensation of focus.

TABLE 2. EVALUATION OF THE METHODOLOGICAL QUALITY OFTHE STUDIES FOUND

\begin{tabular}{l|l} 
Studies selected & Yes \\
\hline Was there randomization? & 21 \\
\hline Was there a control group? & 20 \\
\hline Was it double-blind? & 21 \\
\hline Was the dropout rate described? & 21 \\
\hline The time of the evaluation of results was similar in all groups? & 21 \\
\hline
\end{tabular}

(Source: Based on Berger \& Alperson ${ }^{18}$ ). 
It is important to emphasize that the dopaminergic system participates in the adjustment of the glutamatergic system by means of the basal ganglia and interacts with the PFC and subcortical structures. In a imaging study (such as positron emission tomography [PET]) it was found that during meditation, there is a significant increase in dopamine level $\mathbf{s}^{31}$.

Another important effect observed after the practice of transcendental meditation was a decrease in sensitivity to pain ${ }^{32-34}$. The studies compiled showed that practitioners of the transcendental technique present a significant reduction in blood pressure and heart rate. The significant changes in blood pressure (systolic and diastolic) may be related to changes in the levels of psychological distress, such as anxiety, depression and the ability of social confrontation. This physio-behavioral relationship became a study model, in which psychological distress triggers a heightened activation of the sympathetic autonomic nervous system and the activation of the hypothalamic-pituitary-adrenal axis ${ }^{35}$.

It appears that transcendental meditation promotes the reduction of stress and anxiety levels, which can be explained by the significant decrease in cortisol ${ }^{36}$ and 37 noradrenaline levels, along with increasing concentrations of dopamine plasma dopamine and serotonin ${ }^{39} 38$ (Table 3). The increase of the serotonergic activity can be related to the stimulation of the lateral hypothalamus; the hypothalamic innervation in the pineal gland contributes to the increase in the synthesis and release of serotonin.

The decrease of cortisol and noradrenaline and the dopaminergic increase are associated with the decrease of cardiac and respiratory frequency ${ }^{40}$, taking into account that during the meditative practice there is less sympathetic stimulation and more parasympathetic stimulation. The increased activity of the parasympathetic system would result in a lower inhibition of the GABAergic system at a bulbar level, triggering changes in blood pressure, respiratory fre- quency, motility, and functioning of the gastrointestinal system, improved memory, decreased anxiety and improvement in the sensation of well-being, due to the dopaminergic increase.

\section{Cognitive/behavioral aspects}

The effect of the meditative techniques has been studied in different health conditions, such as depression, anxiety, eating disorders and problems caused by the use of psychoactive drugs ${ }^{42.43}$. The influence of meditation on stress reduction, in the prevention of psychosomatic disorders, in the control of changes in blood pressure and other metabolic diseases ${ }^{44}$, in the control of chronic pain, respiratory, musculoskeletal, and skin problems are also the object of current studies ${ }^{45}$.

In spite of the few studies that relate the effects of meditative techniques with cognitive and behavioral aspects, it is already known that its practice can have a positive influence on the improvement of cognitive functions in attention ${ }^{46},{ }^{47}$ and promote the improvement of verbal fluency and memory ${ }^{48}$.

Some of the studies included in this review claim that the association of transcendental meditation practice and the use of medicines for anxiety promotes greater clinical improvement in general when compared to the use of medication alone. Other studies show that practitioners of TM exhibit greater autonomous stability, which can be inferred from experiments that evaluate the spontaneous dermal resistance ${ }^{49}$. The systems activated in meditation have direct influence in the increase of cerebral perfusion in the prefrontal, parietal and auditory cortex regions ${ }^{48}$, a protective effect on the thickness of the gray mass ${ }^{50}$ in elderly patients, greater stimulation in the areas involved with attention ${ }^{51}$, increase in the strength of cognitive circuits ${ }^{52}$. In addition, meditation can improve the process of myelination or restructuring of the white matter, associated with the anterior cingulate cortex. Another effect of medita-

TABLE 3: CHANGES IN NEUROTRANSMISSION AND STRUCTURAL SYSTEMS IN THE CNS

\begin{tabular}{l|l|l|l} 
Neurotransmitter & Change & Structure in the CNS & Reference \\
\hline Gaba & Increase & Thalamus / inhibitory structures & Guglietti et al. ${ }^{\mathbf{3 0}, 2013}$ \\
\hline Cortisol & Decrease & Paraventricular nucleus & MacLean et al. ${ }^{\mathbf{3 6}}, \mathbf{1 9 9 7}$ \\
\hline Glutamate & Increase & Diffuse in the CNS & Armony \& Ledoux ${ }^{\mathbf{2 7}}, 1999$ \\
\hline Serotonin & Increase & Raphe nuclei & Bujatti \& Biederer ${ }^{\mathbf{3 8}, 1976}$ \\
\hline Noradrenaline & Decrease & Locus coeruleus & Mills \& Farrow ${ }^{\mathbf{4 0}, 1981}$ \\
\hline Dopamine & Increase & Substantia nigra & Infante et al. ${ }^{\mathbf{3 9}}, 2001$ \\
\hline
\end{tabular}

(Source: Based on Newberg \& Iversen ${ }^{41}, 2003$ ). 
tion is neuroprotection; with the decrease in the synthesis and release of cortisol, there is stress reduction, which may be associated with the volume of the hippocampus region in meditation practitioners ${ }^{53}$.

Transcendental meditation practitioners showed better musical and textual memory ${ }^{54.55}$, which may be justified by the possible activation of the amygdala and hippocampus, possibly resulting in better memory consolidation and learning. Finally, meditation practitioners feel a positive impact on the decrease of oxidative stress, which can reduce the risk of neural vascular diseases as well as Alzheimer ${ }^{56}$.

Other studies have shown that in other types of meditation, such as mindfulness, Buddhist and yoga there is a consistent effect on activation in several regions related to the limbic system that reflect on behavior, such as the caudate nucleus, putamen, thalamus, hippocampus, posterior and anterior cingulate cortex, precuneus, Insular lobe, fusiform gyrus, orbitofrontal cortex, occipital lobe, cerebellum, regions of the parietal and temporal gyrus, among others ${ }^{57}$.

The practice of meditation is effective for the significant decrease of the severity of symptoms in patients with obsessive-compulsive disorder, decreasing the obsessions, anxiety and depression epi$\operatorname{sodes}^{58}$. There is also a significant effect in relation to family, social, and professional relationships and in the quality of life of patients who adhered to the practice of meditation in addition to psychotherapeutic treatment. Other studies also show that there is less activation of the amygdala, an area known to play an important role in the processes related to emotional stimuli, which may justify the improvement in the quality of life $\mathrm{e}^{59}$.

This article seeks to present the philosophical origins and some of the current scientific evidence regarding transcendental meditation and its neurophysiological, cognitive/behavioral, and neurochemical effects on practitioners. Some current mind-body approaches have been increasingly integrated into health care. However, in TM, the spiritual aspects are part of its very nature since this practice is based on eastern spiritual traditions.

The present study presents a small but growing number of well-conducted experimental studies. Additional research is needed to understand in more detail what are the mechanisms of action involved in $\mathrm{TM}$. There is great heterogeneity in meditation techniques, and there are few studies that compare these different methods. The meditation techniques can have different effects on the brain and, consequently, in neurophysiology and cognition ${ }^{6}$. Despite this, it is possible to observe that transcendental meditation techniques are a promising health intervention, alone or as a complement to conventional treatment, given the benefits described in this review.

\section{Future challenges}

Further studies are needed to improve the understanding of this area. It would be important to explore innovative and different study designs, as well as examine meditation practitioners in different contexts and conditions.

A recent study examined the brain of a single individual isolated in a retreat for 5.5 weeks. A highlight of this study was its experimental design adapted to observe the response of a single-case study, comparing neuroimaging data pre- and post-intervention. Conventional studies, which analyze groups, take into account the variability between subjects in the statistical analyses, while this approach considered variability in a single subject during the sessions. Repeated observations were required to consider the measurement of errors that could occur for different reasons, such as lack of homogeneity of field or subtle head movements. As a result, the neuroimaging data showed reductions in visual cortices, Brodmann area, and anterior cingulate cortex; the amplitude of low-frequency fluctuations increased in the dorsolateral prefrontal cortex ${ }^{60}$.

This study investigated differences in functional connectivity of the neural network in default mode between frequent practitioners of meditation and non-practitioners in relation to the focus of attention. The participants were instructed to name the color of simple words presented visually in a task called the Stroop Word-Color (SWCT), adapted for functional magnetic resonance (fMRI). The task was performed when the participants were not formally meditating. The logistic analysis based on neuroimaging studies showed that the connectivity between the right and left posterior cingulate cortex and the parietal lobes helps differentiate frequent meditation practitioners from non-practitioners since it may represent a higher degree of interference and distraction during the SWCT in non-practitioners compared with frequent practitioners $^{61}$.

There is another line of research on the modulating impact of meditation on age-related changes in 
the macrostructure of the brain that suggests that meditation can slow down the degeneration of the brain related to age ${ }^{62.63}$. Some studies show less pronounced negative correlations between the chronological age and brain measurements (for example, volumes of local and global gray matter, or indicators of the integrity of fiber from the white matter) in meditation practitioners than in controls ${ }^{64.65}$. However, because these are cross-sectional studies, it is not possible to infer whether meditation induced the differences observed if the differences existed before the individuals initiated the practice, or whether the differences were due to more complex interactions with other factors.

In the studies mentioned above, which are innovative, different techniques of meditation were used. It would be appropriate to check if these results are reproduced by comparing them with the practice of transcendental meditation. There are few studies comparing different meditation techniques.

\section{CONCLUSION}

It is concluded that the TM produces documentable neurochemical, neurophysiological, and cognitive-behavioral effects in its practitioners, both positive and significant. Among the main effects are decreased anxiety and stress (due to the decrease in cortisol and noradrenaline levels), increased sensation of pleasure and well-being (due to an increase in the synthesis and release of dopamine and serotonin) and influence on the recall and possible consolidation of memory. Further studies are needed using creative and innovative methodological designs that analyze different neural circuitry and verify the clinical impact on practitioners.

\section{RESUMO}

O termo meditação pode ser utilizado de diversas formas, de acordo com a técnica a que se refere. A meditação transcendental (MT) é uma dessas técnicas meditativas. A MT pode ser um modelo para pesquisas de meditação espiritual, diferentemente de técnicas de meditação baseadas em uma compreensão secular. O presente estudo objetiva realizar uma revisão bibliográfica para organizar as evidências científicas sobre os efeitos da MT sobre a neurofisiologia, neuroquímica e aspectos cognitivos e comportamentais dos seus praticantes. Para a realização desta revisão narrativa crítica da literatura, foi realizado um levantamento dos artigos científicos presentes na base de dados PubMed do National Center for Biotechnology Information. As palavras-chave utilizadas na busca foram Transcendental Meditation, Neuroscience of meditation e Meditation and behavior. Foram selecionados 21 artigos que analisavam diferentes aspectos que poderiam ser alterados pela prática meditativa. Conclui-se que a MT produz efeitos neuroquímicos, neurofisiológicos e cognitivo-comportamentais documentáveis em seus praticantes, de caráter positivo e significativo. Entre os principais efeitos estão a diminuição da ansiedade e do estresse (via diminuição nos níveis de cortisol e noradrenalina), aumento na sensação de prazer e bem-estar (em decorrência ao aumento na síntese e liberação de dopamina e serotonina) e influência na evocação e possível consolidação da memória. São necessários mais estudos utilizando desenhos metodológicos inovadores e criativos, analisando diferentes circuitos neurais e verificando o impacto clínico sobre os praticantes.

PALAVRAS-CHAVE: Meditação. Terapias mente-corpo. Terapias complementares. Neurofisiologia.

\section{REFERENCES}

1. Johnson W. Introdução. In: Do Xamanismo à Ciência: uma história da meditação. São Paulo: Editora Cultrix; 1995.

2. Goleman D. A mente meditativa: as diferentes experiências meditativas no Oriente e no Ocidente. São Paulo: Ática; 1998.

3. Sinha SS, Jain AK, Tyagi S, Gupta SK, Mahajan AS. Effect of 6 months of meditation on blood sugar, glycosylated hemoglobin, and insulin levels in patients of coronary artery disease. Int J Yoga. 2018;11(2):122-8.

4. Wallace RK, Benson H, Wilson AF. A wakeful hypometabolic physiologic state. Am J Physiol. 1971;221(3):795-9.

5. Bloomfield HH. TM: Discovering inner energy and overcoming stress. New York: Delacorte Press; 1975.

6. Rubia K. The neurobiology of Meditation and its clinical effectiveness in psychiatric disorders. Biol Psychol. 2009;82(1):1-11.

7. Patanjali. The yoga sutras of Patanjali. Alistair; 1993.
8. Wachholtz AB, Pargament KI. Is spirituality a critical ingredient of meditation? Comparing the effects of spiritual meditation, secular meditation, and relaxation on spiritual, psychological, cardiac, and pain outcomes. j Behav Med. 2005;28(4):369-84.

9. Unruh AM, Versnel ], Kerr K. Spirituality unplugged: a review of commonalities and contentions, and a resolution. Can J Occup Ther. 2002;69(1):519.

10. Alexander CN, Rainforth MV, Gelderloos P. Transcendental meditation, self-actualization, and psychological health: a conceptual overview and statistical meta-analysis. J Social Behavior Personality. 1991;6(5):189-248.

11. Dillbeck MC. The effect of the Transcendental Meditation technique on anxiety level. J Clin Psychol. 1977;33(4):1076-8.

12. Nidich $S$, Seeman W, Dreskin T. Influence of transcendental meditation: a replication. J Counseling Psychol. 1973;20(6):565-6. 
13. Schecter $\mathrm{H}$. The Transcendental Meditation program in the classroom A psychological evaluation [Doctoral thesis]. North York: York University; 1977 .

14. Orme-Johnson DW. Autonomic stability and Transcendental Meditation. Psychosom Med. 1973;35(4):341-9.

15. Jevning R, Wilson A, Vanderlaan E, Levine S. Plasma prolactin and cortisol during transcendental meditation. In: Proceedings of the Endocrine Society;1975. p.257.

16. Tomljenović $H$, Begić $D$, Maštrović Z. Changes in trait brainwave power and coherence, state and trait anxiety after three-month transcendental meditation (TM) practice. Psychiatr Danub. 2016;28(1):63-72.

17. Nidich SI, Rainforth MV, Haaga DA, Hagelin J, Salerno JW, Travis F, et al A randomized controlled trial on effects of the Transcendental Meditation program on blood pressure, psychological distress, and coping in young adults. Am J Hypertens. 2009;22(12):1326-31.

18. Berger VW, Alperson SY. A general framework for the evaluation of clinical trial quality. Rev Recent Clin Trials. 2009;4(2):79-88.

19. Travis F, Haaga DA, Hagelin I, Tanner M, Arenander A, Nidich S, et al. A self-referential default brain state: patterns of coherence, power, and eLORETA sources during eyes-closed rest and Transcendental Meditation practice. Cogn Process. 2010;11(1):21-30

20. Yamamoto S, Kitamura Y, Yamada N, Nakashima Y, Kuroda S. Medial prefrontal cortex and anterior cingulate cortex in the generation of alpha activity induced by transcendental meditation: a magnetoencephalographic study. Acta Med Okayama. 2006;60(1):51-8.

21. Newberg A, Travis F, Wintering N, Nidich S, Schneider R. Cerebral glucose metabolic changes associated with a meditation based relaxation technique. J Nucl Med. 2006;47(suppl 1):314P.

22. Pardo JV, Fox PT, Raichle ME. Localization of a human system for sustained attention by positron emission tomography. Nature. 1991;349(6304):61-4

23. Vogt BA, Finch DM, Olson CR. Functional heterogeneity in cingulate cortex: the anterior executive and posterior evaluative regions. Cerebral Cortex. 1992;2(6):435-43.

24. Newberg A, Alavi A, Baime M, Pourdehnad M, Santanna J, d'Aquili, E. The measurement of regional cerebral blood flow during the complex cognitive task of meditation: a preliminary SPECT study. Psychiatry Res. 2001;106(2):113-22.

25. Cornwall J, Phillipson OT. Mediodorsal and reticular thalamic nuclei receive collateral axons from prefrontal cortex and laterodorsal tegmenta nucleus in the rat. Neurosci Lett. 1988;88(2):121-6.

26. Cheramy A, Romo R, Glowinski J. Role of corticostriatal glutamatergic neurons in the presynaptic control of dopamine release. Neurotransmitter Interactions Basal Ganglia. 1987;131-3.

27. Armony |L, LeDoux |E. How danger is encoded: towards a systems, cellular, and computational understanding of cognitive-emotional interactions. Cambridge: MIT Press; 1999. p.1067-79.

28. Bucci DJ, Conley M, Gallagher M. Thalamic and basal forebrain cholinergic connections of the rat posterior parietal cortex. Neuroreport. 1999;10(5):941-5.

29. Destexhe A, Contreras D, Steriade M. Mechanisms underlying the synchronizing action of corticothalamic feedback through inhibition of thalamic relay cells. J Neurophysiol. 1998;79(2):999-1016.

30. Guglietti CL, Daskalakis Z|, Radhu N, Fitzgerald PB, Ritvo P. Meditation-related increases in GABAB modulated cortical inhibition. Brain Stimul. 2013;6(3):397-402.

31. Kjaer TW, Bertelsen C, Piccini P, Brooks D, Alving J, Lou HC. Increased dopamine tone during meditation-induced change of consciousness. Brain Res Cogn Brain Res. 2002;13(2):255-9.

32. Alexander CN, Swanson GC, Rainforth MV, Carlisle TW, Todd CC, Oates Jr RM. Effects of the transcendental meditation program on stress reduction, health, and employee development: a prospective study in two occupational settings. Anxiety, Stress and Coping: Intern J. 1993;6(3):245-62.

33. Haratani T, Henmi T. Effects of transcendental meditation on health behavior of industrial workers. Jpn J Public Health. 1990;37:729.

34. Heidelberg R. Transzendentale meditation in der geburtshilflichen psychoprophylaxe [thesis] Berlin: Medical Faculty, Free University of Berlin; 1979. In: Chalmers RA, Clements G, Schenkluhn H, Weinless M, eds. Scientific research on Maharishi's Transcendental Meditation and TM-Sidh program: collected papers. 3. Vlodrop: Maharishi Vedic University Press; 1989. p.1792-814
35. Julius $S$, Nesbitt $S$. Sympathetic overactivity in hypertension. A moving target. Am J Hypertens. 1996;9(11):113S-20S.

36. MacLean CR, Walton KG, Wenneberg SR, Levitsky DK, Mandarino JP, Waziri $R$, et al. Effects of the Transcendental Meditation program on adaptive mechanisms: changes in hormone levels and responses to stress after 4 months of practice. Psychoneuroendocrinology. 1997;22(4):277-95.

37. Mills PJ, Schneider RH, Hill D, Walton KG, Wallace RK. Beta-adrenergic receptor sensitivity in subjects practicing transcendental meditation. Psychosom Res. 1990;34(1):29-33.

38. Bujatti M, Biederer P. Serotonin, noradrenaline, dopamine metabolites in transcendental meditation-technique. J Neural Transm. 1976;39(3):257-67.

39. Infante JR, Torres-Avisbal M, Pinel P, Vallejo JA, Peran F, Gonzalez F, et al. Catecholamine levels in practitioners of the transcendental meditation technique. Physiol Behav. 2001;72(1-2):141-6.

40. Mills WW, Farrow JT. The transcendental meditation technique and acute experimental pain. Psychosom Med. 1981;43(2):157-64.

41. Newberg $A B$, Iversen I. The neural basis of the complex mental task of meditation: neurotransmitter and neurochemical considerations. Med Hypotheses. 2003;61(2):282-91.

42. Balaji PA, Varne SR, Ali SS. Physiological effects of yogic practices and transcendental meditation in health and disease. N Am | Med Sci. 2012;4(10):442-8

43. Lakhan SE, Schofield KL. Mindfulness-based therapies in the treatment of somatization disorders: a systematic review and meta-analysis. PLoS One. 2013;8(8):e71834

44. Grossman P, Niemann L, Schmidt S, Walach H. Mindfulness-based stress reduction and health benefits. A meta-analysis. J Psychosom Res. 2004;57(1):35-43.

45. Ospina MB, Bond $K$, Karkhaneh M, Tjosvold L, Vandermeer B, Liang Y, et al. Meditation practices for health: state of the research. Evid Rep Techno Assess (Full Rep). 2007;(155):1-263

46. Alexander CN, Langer EJ, Newman RI, Chandler HM, Davies JL. Transcendental meditation, mindfulness, and longevity: an experimental study with the elderly. J Pers Soc Psychol. 1989;57(6):950-64.

47. Prakash R, Rastogi P, Dubey I, Abhishek P, Chaudhury S, Small B). Long-term concentrative meditation and cognitive performance among older adults. Neuropsychol Dev Cogn B Aging Neuropsychol Cogn. 2012;19(4):479-94.

48. Newberg AB, Wintering $N$, Khalsa DS, Roggenkamp $H$, Waldman MR. Meditation effects on cognitive function and cerebral blood flow in subjects with memory loss: a preliminary study. I Alzheimers Dis. 2010;20(2):517-26.

49. Dillbeck MC, Orme-Johnson DW. Physiological differences between transcendental meditation and rest. Am Psychol. 1987;42(9):879-81.

50. Pagnoni G, Cekic M. Age effects on gray matter volume and attentional performance in Zen meditation. Neurobiol Aging. 2007;28(10):1623-7.

51. Lazar SW, Kerr CE, Wasserman RH, Gray JR, Greve DN, Treadway MT, et al. Meditation experience is associated with increased cortical thickness. Neuroreport. 2005;16(17):1893-7.

52. Xiong GL, Doraiswamy PM. Does meditation enhance cognition and brain plasticity? Ann N Y Acad Sci. 2009;1172:63-9.

53. Turakitwanakan W, Mekseepralard C, Busarakumtragul P. Effects of mindfulness meditation on serum cortisol of medical students. J Med Assoc Thai. 2013;96(Suppl 1):S90-5.

54. Travis F, Tecce ||, Guttman |. Cortical plasticity, contingent negative variation, and transcendent experiences during practice of the Transcendental Meditation technique. Biol Psychol. 2000;55(1):41-55.

55. Pagano RR, Frumkin LR. The effect of transcendental meditation on right hemispheric functioning. Biofeedback Self Regul. 1977;2(4):407-15.

56. Reitz C. Dyslipidemia and the risk of Alzheimer's disease. Curr Atheroscler Rep. 2013;15(3):307.

57. Acevedo BP, Pospos S, Lavretsky H. The neural mechanisms of meditative practices: novel approaches for healthy aging. Curr Behav Neurosci Rep. 2016:3(4):328-39.

58. Simpson HB, Foa EB, Liebowitz MR, Ledley DR, Huppert JD, Cahill S, et al. A randomized, controlled trial of cognitive-behavioral therapy for augmenting pharmacotherapy in obsessive-compulsive disorder. Am | Psychiatry. 2008;165(5):621-30 
59. Fox KC, Nijeboer S, Dixon ML, Floman JL, Ellamil M, Rumak SP, et al. Is meditation associated with altered brain structure? A systematic review and meta-analysis of morphometric neuroimaging in meditation practitioners. Neurosci Biobehav Rev. 2014;43:48-73.

60. Sato JR, Kozasa EH, Wallace BA, Amaro E. Neuroimaging data from a single participant before and after a meditation retreat: a proof of concept study. J Cognitive Enhancement. 2017;1(2):235-41.

61. Kozasa EH, Sato IR, Russell TA, Barreiros MAM, Lacerda SS, Radvany $J$, et al. Differences in default mode network connectivity in meditators and non-meditators during an attention task. | Cognitive Enhancement. 2017;1(2):228-34.
62. Luders $E$. Exploring age-related brain degeneration in meditation practitioners. Ann N Y Acad Sci. 2014;1307:82-8.

63. Luders E, Cherbuin N, Kurth F. Forever Young(er): potential age-defying effects of long-term meditation on gray matter atrophy. Front Psychol. 2015;5:1551.

64. Kurth F, Luders E, Wu B, Black DS. Brain gray matter changes associated with mindfulness meditation in older adults: an exploratory pilot study using voxel-based morphometry. Neuro. 2014;1(1):23-6.

65. Laneri D, Schuster $V$, Dietsche B, Jansen A, Ott U, Sommer J. Effects of long-term mindfulness meditation on brain's white matter microstructure and its aging. Front Aging Neurosci. 2016;7:254 